phanacius, Dorotheus und Mamas, die teilweise zu Belisars Leibwache gehörten, zum Einsatz. $^{9}$

Die Isaurier stellten jedoch keineswegs immer die kampferprobten Truppenteile und Leibgarden, sondern sie wurden des öfteren alle im Gefecht niedergehauen, ohne Gegenwehr geleistet zu haben, da sie ,vom Pflug weg" rekrutiert worden waren. ${ }^{10}$ Die Rekrutierung isaurischer Hilfstruppen setzte sich in der byzantinischen Zeit fort: Im Perserkrieg des Caesars Tiberios Konstantinos unter Justin Il. im Jahr 575 kämpften Isaurier. "1

Die isaurischen Regimenter in Justinians Armee sind eher ein Beleg für die Gleichstellung mit anderen Föderatentruppen, unterschiedslos z. B. zu den hunnischen, als für eine gelungene Rückintegration. Ihre Bezeichnung und Nennung im Kontext mit anderen Barbaren läßt sie als Fremdkörper erscheinen; die Isaurier sind nun gleichsam Gastarbeiter wie die übrigen Barbaren in einem Heer, das ohnehin kaum mehr aus „Rhomäern“ bestand.

\title{
3. Isaurische Baumeister?
}

Nicht nur als Soldaten in Justinians Armeen, sondern auch als Wanderarbeiter treten die Isaurier seit dem frühen 6. Jahrhundert auf. ${ }^{12}$ Ihrer Existenz wird von einigen Forschern als Argument für eine erneute Integration in das Reich als Vollbürger ge-

9 Proc. BP I 18, 5 (ein zehntel Isaurier, 2000). 7 (Longinus und Stephanacius); Mal. XVIII 60 p. 463f. (Z. 21: Dorotheus und Mamas); PLRE III 795 s.n. 'Longinus 1', 1183 s.n. 'Stephanacius', 421 s.n. 'Dorotheus 4', 808f., s.n. 'Mamas'; Mal. XVIII 26 p. 441 f; Agathias II 20, 9; Euagr. h.e. V 14 (Isaurier).

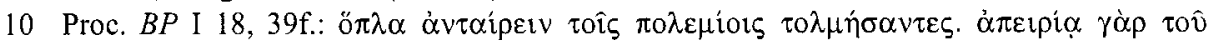

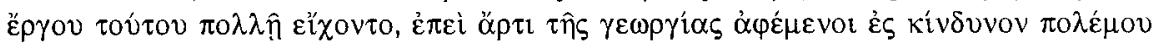

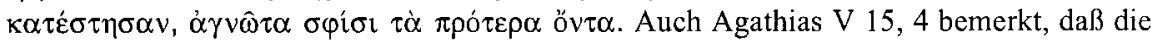
schon von Zeno in Dienst genommenen Isaurier über keinerlei militärische Qualifikation verfügten. Eine zweite Version der Expositio, die wohl nach den Erfolgen des Justinian entstanden ist, schreibt dann auch einfach Isauria quae viros fortes et latrocinantes emittit; ROUGÉ (1966) 312f., Anm. 8.

11 DitTen (1993) 127. Daß die von Prokop explizit so genannten isaurischen Regimenter ausschließlich aus Isauriern bestanden, bezweifelt ELTON (2000a) 295. (2000b) 395 mit Hinweis auf die kappadokische Abstammung des in der V. Sabae des Cyrill Scythopolitanus genannten Konon, s.o. Kap. V.1.1.

12 Holl (1904) 21 u. Anm. 2: Verweis auf den Brief des Gregor von Nyssa ep. 25, ed. Pierre Maraval, SC 363, Paris1990, an Amphilochius von Iconium mit der Bitte um Fach-

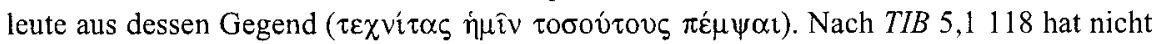
unbedingt wirtschaftliche Not die isaurischen Wanderhandwerker in die Antiochene getrieben, es kann sich auch um Spezialisten gehandelt haben, deren Wissen besonders nach den Erdbeben gefragt war. 
nommen. ${ }^{13}$ Allerdings tauchen sie in den fraglichen Quellen immer zusammen mit weiteren Fremdarbeitern auf. Vor allem beim Bau des Klosters des jüngeren Simeon Stylites auf dem Sinai seien ausschließlich isaurische Fachleute beteiligt gewesen. ${ }^{14}$ Gegen diese These wendet sich jedoch überzeugend der Herausgeber der Vita des jüngeren Simeon. ${ }^{15}$ Im Text heißt es lediglich, aus dem Land der Isaurier seien viele Menschen zum Bau des Klosters herbeigeeilt. ${ }^{16}$ Auch die übrigen Stellen in der Vita sowie ein Kapitel aus der Vita der Hl. Martha zeigen auf, daß die Isaurier nicht als Spezialisten, sondern als kranke Pilger auf den Sinai kamen, die nach ihrer Heilung aus Dankbarkeit noch blieben, um bei den Bauarbeiten zu helfen. ${ }^{17}$ Dennoch läßt sich ein vermehrtes Nennen von Isauriern in den Quellen, die von Baumaßnahmen berichten, nicht leugnen. Beim Einsturz eines Teils an der östlichen Apsis der Hagia Sophia im Jahr 558 erwähnt Malalas dort arbeitende Isaurier. ${ }^{18}$

Die lange Forschungskontroverse, ob eine Reihe der isaurisch-kilikischen Kirchen Kuppelbasiliken gewesen sind und damit Prototypen für die Hagia Sophia gebildet haben oder nicht, dauert an. Archäologisch nachzuweisen sind größere Kuppelbauten in isaurischen Kirchenbauten nicht, die meisten Forscher nehmen deshalb mittlerweile Holzdachkonstruktionen an. ${ }^{19}$

13 Mango (1966); Hill (1996) 9; Dagron / Callot (1998).

14 Mango (1966); V. Simeonis Stylitiae Iunioris, s. auch KW 291, 108.

15 So VAN DEN VEN II (1970) 92, Anm. 2: Ihre Rolle sei von MANGO (1966), stark übertrieben" worden.

$16 V$. Simeonis Stylitiae Iunioris 96 mit VAN DEN VEN II (1970) 92, Anm. 2, 179, Anm. 1 zu V. Simeonis Stylitiae Iunioris 172.

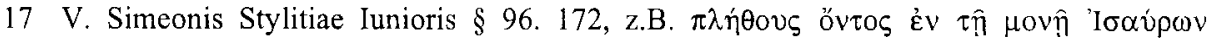

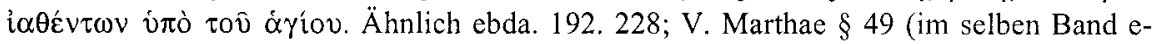
diert) mit VAN DEN VEN I (1962) 203. II (1970) 92, Anm. 2. 179, Anm. 1. 194, Anm. 1. 225f., Anm. 1. Nur der in V. Simeonis Stylitiae Iunioris 188 beschriebene Isaurier mit dem Lähmungswunder, vgl. o. Kap. 2, arbeitete als Steinmetz - und dies ist der einzige explizit als Spezialist bezeichnete Arbeiter überhaupt.

18 Mal. XVIII 128 p. 490; vgl. Theoph. AM 6050; vgl. Mango (1966) 364f.

19 Josef StrZYgowsKI, Kleinasien, Ein Neuland der Kunstgeschichte, Leipzig 1903, $110 \mathrm{f}$. und die Ausgräber von Meriamlik / Ayatekla im Jahre 1907, Ernst HERzFELD und Samuel GUYER, MAMA II (1930), 61f. hatten eine Kuppel bei der Zenokirche in Ayatekla angenommen, obgleich sie HEADLAM (1893) für den Fall von Alahan mit dem Holzdach folgten. HEADLAM (1893) hatte auch für Ayatekla die Möglichkeit der Holzdachkonstruktion vorgezogen, gefolgt von FORSYTH (1957) in seiner Replik auf MAMA II., der ein oktagonales Holzdach annahm, das auf dekorierten Vorsprüngen ruhte, FoRSYTH (1957) 225: „Domes seem to have an irresistible attraction for some architectural historians." Das Stützmauerwerk in Meriamlik ist, anders als bei MAMA II 61 behauptet, zu schwach, um eine Steinkuppel zu tragen. Auch im anders als in Meriamlik / Ayatekla vom Steinraub verschonten Alahan hat GougH (1985) keinerlei Überreste einer Steinkuppel gefunden; vgl. auch GougH (1972) 202f. Anders wieder Hill (1996) 72, 230f.: Es sei beim Bau experimentiert worden in Richtung der Kuppeln, wobei es eine Verbindung zwischen den 